\title{
Balanced reciprocal translocation at amniocentesis: cytogenetic detection and implications for genetic counseling
}

\author{
H.G. Zhang, X.Y. Zhang, H.Y. Zhang, T. Tian, S.B. Xu and R.Z. Liu \\ Center for Reproductive Medicine, Center for Prenatal Diagnosis, First Hospital, \\ Jilin University, Changchun, Jilin, China \\ Corresponding author: R.Z. Liu \\ E-mail: 1rz410@126.com \\ Genet. Mol. Res. 15 (3): gmr.15038556 \\ Received February 15, 2016 \\ Accepted April 8, 2016 \\ Published August 18, 2016 \\ DOI http://dx.doi.org/10.4238/gmr.15038556
}

Copyright (C) 2016 The Authors. This is an open-access article distributed under the terms of the Creative Commons Attribution ShareAlike (CC BY-SA) 4.0 License.

\begin{abstract}
Balanced translocation is a common structural chromosomal rearrangement in humans. Carriers can be phenotypically normal but have an increased risk of pregnancy loss, fetal death, and the transmission of chromosomal abnormalities to their offspring. Existing prenatal screening technologies and diagnostic procedures fail to detect balanced translocation, so genetic counseling for carriers remains a challenge. Here, we report the characteristics of chromosomal reciprocal translocation in 3807 amniocentesis cases. Of the 16 detected cases of fetal reciprocal translocation, 8 cases $(50 \%)$ showed positive biochemical marker screening; 3 cases $(18.75 \%)$ were the parental carriers of a chromosomal abnormality; 2 (12.5\%) were of advanced maternal age, $2(12.5 \%)$ had a previous history of children with genetic disorders, and 1 case $(6.25 \%)$ was associated with positive soft markers in obstetric ultrasound. Chromosomes 5 and 19 were the most commonly involved chromosomes in balanced translocations. Of the 13
\end{abstract}


cases with fetal balanced translocations, $8(61.5 \%)$ were inherited from a paternal chromosome, $3(23.1 \%)$ from a maternal chromosome, and $2(15.4 \%)$ cases were de novo. The incidence of balanced translocation at amniocentesis was $0.42 \%$. Male carriers of reciprocal chromosome translocation appear to have a higher chance of becoming a parent of a child born by normal childbirth than female carriers.

Key words: Balanced translocation; Amniocentesis; Genetic counseling; Giemsa banding (GTG banding)

\section{INTRODUCTION}

Balanced translocations, whereby two different chromosomes exchange segments with no gain or loss of genetic material, are common structural chromosomal rearrangements in humans. Frequency rates have been reported to range from 0.08 to $0.3 \%$ in the general population (Zhang et al., 2015a). Carriers of balanced chromosomal translocations may be phenotypically normal, but are associated with an increased risk of pregnancy loss, fetal death, and the transmission of chromosomal abnormalities to their offspring through the production of a higher number of unbalanced spermatozoa (Godo et al., 2013). Because the carriers of balanced translocations have an increased risk of pregnancy loss, fetal death, and the transmission of chromosomal abnormalities to their offspring, or have a phenotypically normal child, genetic counseling for carriers of balanced translocations remains a challenge. In most couples with recurrent pregnancy loss, the number of female carriers with balanced chromosomal aberrations significantly exceeds that of male individuals (Kochhar and Ghosh, 2013). The success rate of natural pregnancy in couples where men carry translocations ranges from 30 to 70\% (Ozawa et al., 2008). Paoloni-Giacobino et al. (2000) have also reported that carrier males suffer from primary infertility with severe oligoasthenoteratospermia or azoospermia, while at least two of three carrier women are fertile. Patients carrying balanced reciprocal translocations are subject to meiosis nondisjunction risk. Indeed, the mispairing of translocated chromosomes during the first meiotic division can give rise to different forms of segregation, which can result in balanced, unbalanced, and normal gametes of the translocated chromosomes (Pourjafari et al., 2012). The exact formation is dependent on the breakpoints and the chromosomes involved (De et al., 2015).

Several different technologies are used for prenatal screening tests and diagnostic procedures, including ultrasonography, the double-marker test [pregnancy-associated plasma protein $\mathrm{A}$ and free $\beta$-human chorionic gonadotropin $(\beta-\mathrm{HCG})]$, the triple marker test ( $\alpha$-fetoprotein, free $\beta$-HCG, and unconjugated estriol), and array-based comparative genomic hybridization of fetal DNA in the maternal circulation (Sheth et al., 2015). These technologies are, however, limited to detecting the most common aneuploidies such as trisomies 13, 18, and 21, and do not detect balanced translocations (Wapner et al., 2012; Novelli et al., 2013; Konialis and Pangalos, 2015).

Prenatal testing and, alternatively, preimplantation genetic diagnosis (PGD), are recommended aspects of genetic counseling for balanced translocation carriers because these individuals are at an increased risk of implantation failure, miscarriage, or the delivery of affected offspring (Vozdova et al., 2013). Although PGD is currently widely available for and utilized by recurrent miscarriage couples carrying a structural chromosomal abnormality,

Genetics and Molecular Research 15 (3): gmr.15038556 
clinical characteristics including spontaneous abortion do not differ between those couples that accept and those that decline PGD (De Krom et al., 2015).

Hence, reproductive performance and genetic counseling for carriers with balanced translocation merit further research. The present study aimed to assess balanced reciprocal translocation at amniocentesis in Jilin Province, China. Moreover, the relationship between chromosomal breakpoints and reproductive performance is discussed.

\section{MATERIAL AND METHODS}

Women presenting a 16-22-week singleton gestation at the Center for Prenatal Diagnosis, First Hospital, Jilin University, China, for amniocentesis between February 2011 and December 2014 were offered participation in our study. Amniotic fluid cells were obtained by amniocentesis at 16-22 weeks' gestation. The amniocenteses were for indications including advanced maternal age, a positive aneuploidy screening result, abnormal ultrasound, and paternal/maternal carriers. Amniotic fluid cells for centrifugation were cultured in CHANG Amnio ${ }^{\circledR}$ Medium (Irvine Scientific, Santa Ana, CA, USA), followed by treatment with colcemid. A total of 3807 amniocentesis samples (excluding 19 culture failure samples) were processed. They also underwent Giemsa banding (GTG banding) to determine the karyotype using our previously reported methods (Zhang et al., $2015 \mathrm{~b})$. The results were reported according to the recommendations of the International System for Chromosome Nomenclature 2009 (Shaffer et al., 2009).

For cases of fetal chromosomal balanced translocation, we performed cytogenetic analysis of the couples, and suggested genetic counseling if appropriate. Finally, we performed a follow-up to determine the outcome of pregnancy. The process is shown in Figure 1. The study protocol was approved by the Ethics Committee of The First Hospital, Jilin University, Changchun, China, and all participants provided their written informed consent.

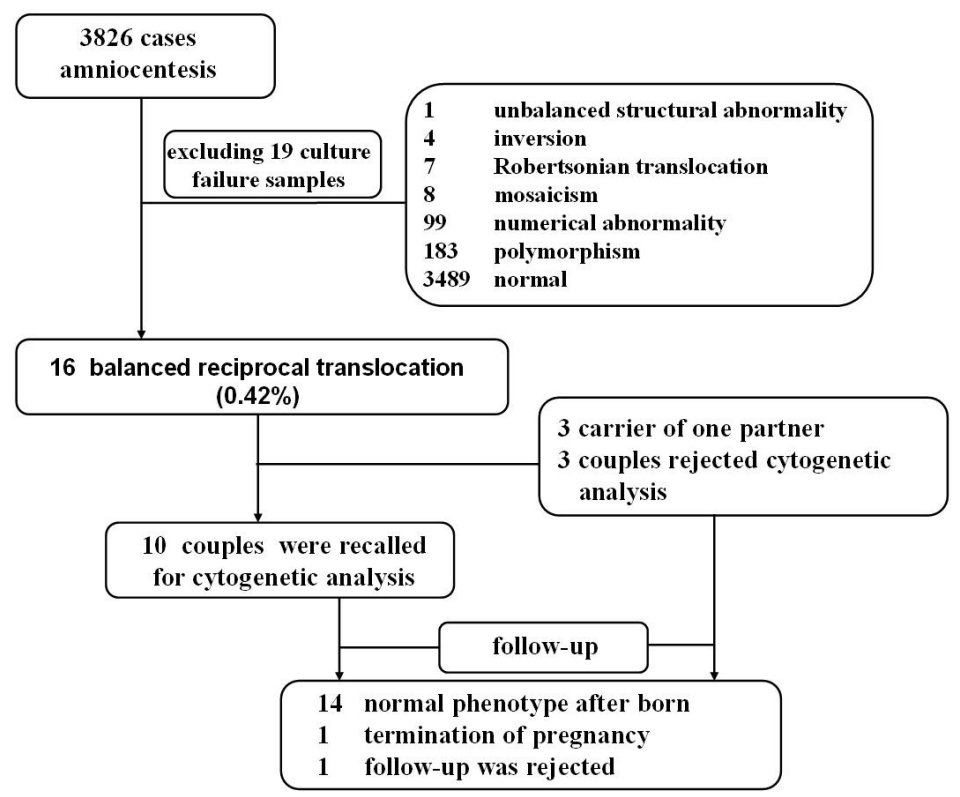

Figure 1. Flow chart of genetic counseling and reproductive choice after amniocentesis.

Genetics and Molecular Research 15 (3): gmr.15038556 


\section{RESULTS}

Of the 3807 amniotic fluid cell chromosomes analyzed, the frequency of balanced translocation was $0.42 \%(16 / 3807)$. Of these, eight $(50 \%)$ cases had positive biochemical marker screening, three (18.75\%) were the parental carriers of a chromosomal abnormality, two $(12.5 \%)$ were studied because of advanced maternal age, two $(12.5 \%)$ had a previous history of children with genetic disorders (children with aneuploidy), and one case (6.25\%) was associated with positive soft markers in obstetric ultrasound (Table 1).

Table 1. Analysis of fetal karyotype and reproductive outcomes.

\begin{tabular}{l|l|c|l|l|l}
\hline Case & Indication for amniocentesis & Maternal age (years) & Fetal karyotype & Familial/de novo & Outcomes after born \\
\hline 1 & Previous aneuploid child & 27 & $46, \mathrm{XN}, \mathrm{t}(5 ; 20)(\mathrm{q} 13 ; \mathrm{q} 12)$ & Paternal & Normal phenotype \\
\hline 2 & Advanced maternal age & 36 & $46, \mathrm{XN}, \mathrm{t}(17 ; 19)(\mathrm{p} 11 ; \mathrm{q} 13)$ & Paternal & Normal phenotype \\
\hline 3 & Previous aneuploid child & 34 & $46, \mathrm{XN}, \mathrm{t}(5 ; 11)(\mathrm{p} 14 ; \mathrm{p} 15)$ & Paternal & Normal phenotype \\
\hline 4 & Paternal carrier & 31 & $46, \mathrm{XN}, \mathrm{t}(10 ; 19)(\mathrm{q} 24 ; \mathrm{p} 13.1)$ & Paternal & Normal phenotype \\
\hline 5 & BMS positive & 34 & $46, \mathrm{~N}, \mathrm{t}(\mathrm{X} ; 1)(\mathrm{p} 11 ; \mathrm{q} 11)$ & $?$ & - \\
\hline 6 & Abnormal ultrasound & 34 & $46, \mathrm{XN}, \mathrm{t}(4 ; 14)(\mathrm{q} 13 ; \mathrm{q} 11)$ & Maternal & Normal phenotype \\
\hline 7 & BMS positive & 32 & $46, \mathrm{XN}, \mathrm{t}(1 ; 22)(\mathrm{p} 22 ; \mathrm{q} 11)$ & Paternal & Normal phenotype \\
\hline 8 & BMS positive & 34 & $46, \mathrm{XN}, \mathrm{t}(4 ; 20)(\mathrm{q} 21 ; \mathrm{q} 13.3)$ & De novo & Normal phenotype \\
\hline 9 & BMS positive & 27 & $46, \mathrm{XN}, \mathrm{t}(2 ; 10)(\mathrm{q} 11 ; \mathrm{q} 11)$ & $?$ & Normal phenotype \\
\hline 10 & Maternal carrier & 30 & $46, \mathrm{XN}, \mathrm{t}(17 ; 22)(\mathrm{q} 21 ; \mathrm{q} 11)$ & Maternal & Normal phenotype \\
\hline 11 & Advanced maternal age & 41 & $46, \mathrm{XN}, \mathrm{t}(3 ; 19)(\mathrm{q} 12 ; \mathrm{q} 13)$ & De novo & Normal phenotype \\
\hline 12 & BMS positive & 32 & $46, \mathrm{XN}, \mathrm{t}(5 ; 11)(\mathrm{p} 15 ; \mathrm{q} 13)$ & $?$ & Normal phenotype \\
\hline 13 & BMS positive & 31 & $46, \mathrm{XN}, \mathrm{t}(3 ; 9)(\mathrm{q} 21 ; \mathrm{q} 22)$ & Paternal & Normal phenotype \\
\hline 14 & BMS positive & 30 & $46, \mathrm{XN}, \mathrm{t}(5 ; 13)(\mathrm{q} 13 ; \mathrm{q} 12)$ & Paternal & Termination of pregnancy \\
\hline 15 & Maternal carrier & 24 & $46, \mathrm{XN}, \mathrm{t}(1 ; 13)(\mathrm{p} 22 ; \mathrm{q} 32)$ & Maternal & Normal phenotype \\
\hline 16 & BMS positive & 34 & $46, \mathrm{XN}, \mathrm{t}(3 ; 19)(\mathrm{q} 12 ; \mathrm{q} 13)$ & Paternal & Normal phenotype \\
\hline
\end{tabular}

$\mathrm{BMS}=$ biochemical marker screening.

Fetal karyotypes and abnormal chromosomes are shown in Table 1 and Figure 2, respectively. Chromosomes $5(\mathrm{~N}=4)$ and $19(\mathrm{~N}=4)$ were the most commonly involved chromosomes in the balanced reciprocal translocations (Table 1).

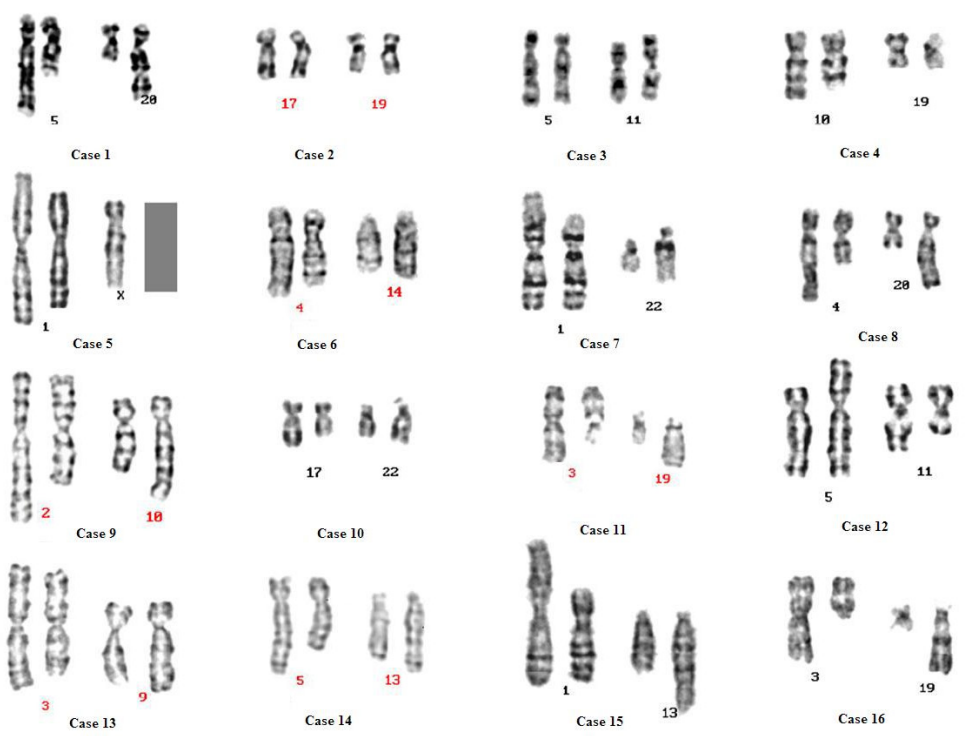

Figure 2. Abnormal fetal karyotype.

Genetics and Molecular Research 15 (3): gmr.15038556 
Although we tried to recall all 16 couples for cytogenetic analysis, three couples refused. Of the other $13,8(61.5 \%)$ cases of fetal balanced reciprocal translocations were shown to be inherited from the paternal chromosome, 3 (23.1\%) were inherited from the maternal chromosome, and two cases $(15.4 \%)$ were de novo (Table 1$)$. Through follow-up, we found that 14 children were born with a normal phenotype. Pregnancy was terminated in one case, and follow-up was refused in another (Table 1).

\section{DISCUSSION}

Microscopy can only detect gross chromosome abnormalities; therefore, chromosomal microarray analysis is used to identify additional, clinically significant cytogenetic information. It is at least as good at identifying aneuploidies and unbalanced rearrangements as karyotyping. However, it is not able to identify balanced translocations or triploidies (Wapner et al., 2012). Instead, it can detect small microdeletions/microduplications (copy number variations) with unknown functional roles and difficult genotype/phenotype correlations. Copy number variation syndromes are often associated with variable phenotypic outcomes, ranging from normal to severely affected individuals. Because of a supposed lack of experience by laboratory staff, clinical geneticists, and counselors at managing the outcomes of microarray-based analysis (Novelli et al., 2013), conventional cytogenetic analysis remains an important method in prenatal diagnosis.

Invasive prenatal diagnostic techniques are feasible tools for confirming fetal chromosomal abnormalities (Zhang et al., 2010), and amniocentesis is a reliable and lowrisk method of achieving suitable genetic material (Grether-González et al., 2010). Routine chromosome analysis has been the gold standard for prenatal cytogenetic diagnosis (Wilson et al., 2009); it identifies reciprocal chromosomal translocations as the most common type of structural chromosomal aberrations in the human population (Vasilevska et al., 2013).

The frequency of balanced reciprocal translocation in the general population is estimated from prenatal and newborn studies to be approximately 1 in $625(0.16 \%)$ (Nonaka et al., 2015). Sheth et al. (2015) detected abnormal karyotypes in 125/1728 cases (7.2\%), with structural abnormalities such as reciprocal and Robertsonian translocation detected in 20 cases (1.2\%). Wu et al. (2013) reported an abnormal fetal karyotype frequency of $4.6 \%$. Structural aberrations of chromosomes were identified in 43 cases, including 21 cases $(0.5 \%)$ of balanced reciprocal translocation. Both Peng et al. (2006) and Chang et al. (2013) reported similar frequencies of reciprocal translocations in amniocentesis cases of $0.44 \%(74 / 16,749)$ and $0.53 \%(66 / 12,468)$, respectively. Specifically, $0.256 \%$ had a reciprocal translocation. Balkan et al. (2011) observed 52 cases (4.9\%) with chromosomal aberrations, of which two were reciprocal translocations, while 41 cases $(0.84 \%)$ were balanced translocations in a study of prenatal cytogenetic examinations by Park et al. (2001). The findings from the present study were in line with these, detecting abnormal karyotypes in $318 / 3807$ cases $(8.35 \%)$, of which $16(0.42 \%)$ were balanced reciprocal translocations.

Indications for amniocentesis include advanced maternal age (AMA), maternal serum screening results, ultrasonographic findings for congenital malformations or markers of aneuploidy, and chromosomal abnormalities in a previous pregnancy (Wilson et al., 2009; Danisman et al., 2013; Suzumori et al., 2015). Positive prenatal screening and AMA are the main clinical indications (Mademont-Soler et al., 2011). Prenatal diagnosis is offered to carriers of a balanced chromosomal rearrangement because they may be predisposed to offspring with an unbalanced karyotype (Bache et al., 2007; Chang et al., 2013). Chang et

Genetics and Molecular Research 15 (3): gmr.15038556 
al. (2013) reported that the highest proportion of reciprocal translocations was found in cases with indications of AMA $(52.7 \%, 39 / 74)$, abnormal biochemical markers in the maternal serum $(12.2 \%, 9 / 74)$, and a parent with an abnormal karyotype $(17.6 \%, 13 / 74)$. Balkan et al. (2011) reported that the highest detection rate of chromosome aberrations was in cases undergoing amniocentesis for abnormal maternal serum screening combined with abnormal ultrasound findings (8.0\%). Meng et al. (2015) reported that over a period of 13 years, the indication of abnormal maternal serum screening and abnormal ultrasound findings increased, while AMA decreased for prenatal diagnosis of cytogenetic abnormalities, and a continuous trend of reduced invasive procedures was observed. The present study showed that of 16 cases of balanced translocation, eight had a positive biochemical marker screening, three were the parental carriers of a chromosomal abnormality, two were studied because of advanced maternal age, two had a previous history of children with genetic disorders, and one case was associated with positive soft markers in obstetric ultrasound.

Infertility and spontaneous abortion are closely associated with reciprocal chromosome translocations. Because of various mechanisms of abnormal meiotic segregation, the size of unbalanced chromosome segments in offspring determines the degree of risk for reproductive abnormalities. To evaluate this risk in different pedigrees, it is important to assess the type of chromosomal translocation and the location of the breakpoints (Midro, 1992). In the present study, chromosomes 5 and 19 were the most commonly affected in the 16 fetal karyotypes with a balanced reciprocal translocation.

Male carriers of reciprocal chromosome translocations have a higher chance of becoming a parent of a child who undergoes normal childbirth than female carriers. Vasilevska et al. (2013) reported six cases of reciprocal translocations of different autosomes, of which five were of paternal origin and one was inherited from the mother. Only the cases of $46, \mathrm{XY}, \mathrm{t}(6 ; 10)$ (p21;q26) pat. and double translocation $46, \mathrm{XX}, \mathrm{t}(1 ; 21) \mathrm{t}(7 ; 16)$ mat. were associated with reproductive problems. Couples with a fetal chromosome $46, \mathrm{XN}, \mathrm{t}(5 ; 20)(\mathrm{q} 13 ; \mathrm{q} 12)$ pat. and $46, \mathrm{XN}, \mathrm{t}(5 ; 11)(\mathrm{p} 14 ; \mathrm{p} 15)$ pat. had a previous child with aneuploidy. Peng et al. (2006) reported an incidence of de novo reciprocal translocations of $0.08 \%$, which is much lower than that observed in the present study (15.4\%). This difference might reflect the low sample number in the present study. In our study, 14 children of the 16 cases with reciprocal chromosome translocations were born with a normal phenotype, so had no reproductive problems.

In conclusion, the incidence of balanced reciprocal translocation at amniocentesis was $0.42 \%$ in Jilin Province, China. The highest proportion of reciprocal translocations was observed in cases with indications of positive biochemical marker screening. Chromosomes 5 and 19 were most commonly involved in fetal karyotypes with a balanced reciprocal translocation. Male carriers of reciprocal chromosome translocations have a higher chance of becoming a parent of a child born by normal childbirth than female carriers.

\section{Conflicts of interest}

The authors declare no conflict of interest.

\section{ACKNOWLEDGMENTS}

We would like to thank all patients for their cooperation. Research supported by the National Natural Science Fund (\#81471515).

Genetics and Molecular Research 15 (3): gmr.15038556 
Balanced reciprocal translocation at amniocentesis

\section{REFERENCES}

Bache I, Brondum-Nielsen K and Tommerup N (2007). Genetic counseling in adult carriers of a balanced chromosomal rearrangement ascertained in childhood: experiences from a nationwide reexamination of translocation carriers. Genet. Med. 9: 185-187. http://dx.doi.org/10.1097/GIM.0b013e3180314671

Balkan M, Akbas H, Kalkanli S, Sakar MN, et al. (2011). Evaluation of clinical and cytogenetic findings on 1,068 secondtrimester amniocenteses in Southeast Turkey. Clin. Exp. Obstet. Gynecol. 38: 364-368.

Chang YW, Wang PH, Li WH, Chen LC, et al. (2013). Balanced and unbalanced reciprocal translocation: an overview of a 30-year experience in a single tertiary medical center in Taiwan. J. Chin. Med. Assoc. 76: 153-157. http://dx.doi. org/10.1016/j.jcma.2012.11.002

Danisman N, Kahyaoglu S, Celen S, Kahyaoglu I, et al. (2013). A retrospective analysis of amniocenteses performed for advanced maternal age and various other indications in Turkish women. J. Matern. Fetal Neonatal Med. 26: 242-245. http://dx.doi.org/10.3109/14767058.2012.733756

De Krom G, Arens YH, Coonen E, Van Ravenswaaij-Arts CM, et al. (2015). Recurrent miscarriage in translocation carriers: no differences in clinical characteristics between couples who accept and couples who decline PGD. Hum. Reprod. 30: 484-489. http://dx.doi.org/10.1093/humrep/deu314

De P, Chakravarty S and Chakravarty A (2015). Novel balanced chromosomal translocations in females with recurrent spontaneous abortions: Two case studies. J. Hum. Reprod. Sci. 8: 114-117. http://dx.doi.org/10.4103/0974$\underline{1208.158623}$

Godo A, Blanco J, Vidal F and Anton E (2013). Accumulation of numerical and structural chromosome imbalances in spermatozoa from reciprocal translocation carriers. Hum. Reprod. 28: 840-849. http://dx.doi.org/10.1093/humrep/ $\underline{\operatorname{des} 431}$

Grether-González P, Cámara-Polanco V, Ulloa-Avilés V, Salas-Labadia C, et al. (2010). [Prenatal diagnosis by amniocentesis. Clinical and cytogenetic experience in 1,500 cases]. Ginecol Obstet Mex 78: 493-503.

Kochhar PK and Ghosh P (2013). Reproductive outcome of couples with recurrent miscarriage and balanced chromosomal abnormalities. J. Obstet. Gynaecol. Res. 39: 113-120. http://dx.doi.org/10.1111/j.1447-0756.2012.01905.x

Konialis C and Pangalos C (2015). Dilemmas in prenatal chromosomal diagnosis revealed through a single center's 30 years' experience and 90,000 cases. Fetal Diagn. Ther. 38: 218-232. http://dx.doi.org/10.1159/000368604

Mademont-Soler I, Morales C, Clusellas N, Soler A, et al.; Group of Cytogenetics from Hospital Clínic de Barcelona (2011). Prenatal cytogenetic diagnosis in Spain: analysis and evaluation of the results obtained from amniotic fluid samples during the last decade. Eur. J. Obstet. Gynecol. Reprod. Biol. 157: 156-160. http://dx.doi.org/10.1016/j. ejogrb.2011.03.016

Meng J, Matarese C, Crivello J, Wilcox K, et al. (2015). Changes in and efficacies of indications for invasive prenatal diagnosis of cytogenomic abnormalities: 13 years of experience in a single center. Med. Sci. Monit. 21: 1942-1948. http://dx.doi.org/10.12659/MSM.893870

Midro AT (1992). [Genetic counseling in the case of carrier state with reciprocal chromosome translocations]. Wiad. Lek. 45: 775-780.

Nonaka T, Ooki I, Enomoto T and Takakuwa K (2015). Complex chromosomal rearrangements in couples affected by recurrent spontaneous abortion. Int. J. Gynaecol. Obstet. 128: 36-39. http://dx.doi.org/10.1016/j.ijgo.2014.07.018

Novelli A, Cavalli P and Bernardini L (2013). The future of prenatal diagnosis: karyotype, microarray or both? Technical and ethical considerations. Expert Rev. Proteomics 10: 131-134.http://dx.doi.org/10.1586/epr.13.9

Ozawa N, Maruyama T, Nagashima T, Ono M, et al. (2008). Pregnancy outcomes of reciprocal translocation carriers who have a history of repeated pregnancy loss. Fertil. Steril. 90: 1301-1304. http://dx.doi.org/10.1016/j. fertnstert.2007.09.051

Paoloni-Giacobino A, Kern I, Rumpler Y, Djlelati R, et al. (2000). Familial t(6;21)(p21.1;p13) translocation associated with male-only sterility. Clin. Genet. 58: 324-328. http://dx.doi.org/10.1034/j.1399-0004.2000.580411.x

Park SY, Kim JW, Kim YM, Kim JM, et al. (2001). Frequencies of fetal chromosomal abnormalities at prenatal diagnosis: 10 years experiences in a single institution. J. Korean Med. Sci. 16: 290-293. http://dx.doi.org/10.3346/ jkms.2001.16.3.290

Peng HH, Chao AS, Wang TH, Chang YL, et al. (2006). Prenatally diagnosed balanced chromosome rearrangements: eight years' experience. J. Reprod. Med. 51: 699-703.

Pourjafari B, Pour-Jafari H, Farimani M, Ghahramani S, et al. (2012). Genetic counseling in carriers of reciprocal translocations involving two autosomes. Indian J. Hum. Genet. 18: 250-253. http://dx.doi.org/10.4103/0971$\underline{6866.100802}$

Genetics and Molecular Research 15 (3): gmr.15038556 
Shaffer LG, Slovak ML and Campbell LJ (2009). Recommendations of the International Standing Committee on Human Cytogenetic Nomenclature (ISCN 2009). An International System for Human Cytogenetic Nomenclature. Karger, Basel, Switzerland.

Sheth F, Rahman M, Liehr T, Desai M, et al. (2015). Prenatal screening of cytogenetic anomalies - a Western Indian experience. BMC Pregnancy Childbirth 15: 90. http://dx.doi.org/10.1186/s12884-015-0519-y

Suzumori N, Kumagai K, Goto S, Nakamura A, et al. (2015). Parental decisions following prenatal diagnosis of chromosomal abnormalities: implications for genetic counseling practice in Japan. J. Genet. Couns. 24: 117-121. http://dx.doi.org/10.1007/s10897-014-9744-1

Vasilevska M, Ivanovska E, Kubelka Sabit K, Sukarova-Angelovska E, et al. (2013). The incidence and type of chromosomal translocations from prenatal diagnosis of 3800 patients in the republic of macedonia. Balkan J. Med. Genet. 16: 23-28. http://dx.doi.org/10.2478/bjmg-2013-0027

Vozdova M, Oracova E, Kasikova K, Prinosilova P, et al. (2013). Balanced chromosomal translocations in men: relationships among semen parameters, chromatin integrity, sperm meiotic segregation and aneuploidy. J. Assist. Reprod. Genet. 30: 391-405. http://dx.doi.org/10.1007/s10815-012-9921-9

Wapner RJ, Martin CL, Levy B, Ballif BC, et al. (2012). Chromosomal microarray versus karyotyping for prenatal diagnosis. N. Engl. J. Med. 367: 2175-2184.http://dx.doi.org/10.1056/NEJMoa1203382

Wilson RD, Blight C and Langlois S (2009). Diagnosing chromosomal abnormalities from "big" to "small" with molecular cytogenetic technology. J. Obstet. Gynaecol. Can. 31: 414-421. http://dx.doi.org/10.1016/S1701-2163(16)34172-X

Wu Q, Wang W, Kong H, Sun L, et al. (2013). Investigation of the frequencies of prenatally diagnosed fetal chromosomal abnormalities at a single institution. Fetal Pediatr. Pathol. 32: 163-168. http://dx.doi.org/10.3109/15513815.2012. $\underline{684847}$

Zhang HG, Wang RX, Li LL, Sun WT, et al. (2015a). Male carriers of balanced reciprocal translocations in Northeast China: sperm count, reproductive performance, and genetic counseling. Genet. Mol. Res. 14: 18792-18798. http:// dx.doi.org/10.4238/2015.December.28.28

Zhang HG, Liu XY, Hou Y, Chen S, et al. (2015b). Reproductive outcome of a case with familial balanced translocation $\mathrm{t}(3 ; 6)$ : implications for genetic counseling. Genet. Mol. Res. 14: 2809-2815. http://dx.doi.org/10.4238/2015. March.31.11

Zhang L, Zhang XH, Liang MY and Ren MH (2010). Prenatal cytogenetic diagnosis study of 2782 cases of high-risk pregnant women. Chin. Med. J. (Engl.) 123: 423-430.

Genetics and Molecular Research 15 (3): gmr.15038556 